\title{
Millettia pinnata: a study on the extraction of fibers and reinforced composites
}

\author{
P. B. Mohankumara ${ }^{1 *} \mathbb{D}$, Shraddha Prashant Thakare², Vijaykumar Guna ${ }^{2,3}$ and G. R. Arpitha ${ }^{4}$
}

\begin{abstract}
In this work, the potential for using Millettia pinnata stalk for extracting cellulosic natural fibers and its subsequent use in reinforced composites was studied. The extracted fibers were characterized for its composition, mechanical, thermal stability and morphological properties. Compositional analysis showed that the fibers possessed 54\% cellulose, $12 \%$ hemicellulose, $15 \%$ lignin and $11 \%$ ash. The tensile strength of the fiber was $310 \mathrm{MPa}$, which is comparable to cotton and linen. The tensile strength of the M. pinnata fiber-reinforced polypropylene composites was $17.96 \mathrm{MPa}$ which was similar to other natural fiber-based composites. M. pinnata fibers appear promising for a wide range of applications including textiles and other typical composites applications.
\end{abstract}

Keywords: Natural fibers, Biopolymers, Lignocellulosic material, Composites, Green materials

\section{Introduction}

Due to increasing awareness of the harmful effects of non-renewable materials, the world is gradually moving towards greener sustainable materials. On that line, natural fibers are being commonly used in various industries because of its high specific strength, low cost, low density, biodegradability and low-to-nil greenhouse emissions (Reddy and Yang 2009). Traditional fiber sources such as cotton, jute are resource intensive and are mainly grown for their fibers which limits the value added to the agricultural practice. Although these traditional sources dominate the world fiber market, a smooth supply of fibers cannot be ensured mainly due to the special growing conditions and extensive resources required. To overcome these limitations, other non-conventional sources of fibers should be considered for multi-fold benefits. One such source of non-conventional fibers is lignocellulosic agricultural residues and byproducts. Agro-residues are generated inevitably in huge quantities without any extra resources, but these valuable residues are generally burned leading to numerous environmental problems.

\footnotetext{
*Correspondence: mohanpb17@gmail.com

${ }^{1}$ Center for Energy Research, S-VYASA University, Jigani, Bangalore,

Karnataka 560105, India

Full list of author information is available at the end of the article
}

Several researchers have studied the potential for using agro-residues and byproducts for various applications such as composites, water purification, bioproducts and so on (Guna et al. 2016, 2017, 2018, 2019a, b, c; Ilangovan et al. 2017, 2018a, 2019 Bhuvaneswari et al. 2017). Researches have also experimented the potential for using agro-residues for fiber extraction which seems to be a good technique to use these abundant raw material (Guna et al. 2019c; Ni et al. 2018; Kalita et al. 2019; Wang et al. 2016; Kale et al. 2018; Mohan et al. 2017; Vinayaka et al. 2017).

Millettia pinnata (M. pinnata) is a plant endemic to Asia and widely distributed in the Indian subcontinent. Locally it is known by various names such as 'Pongamia', 'Karanja,' 'Honge' or 'Pungai'. M. pinnata seeds are widely used to produce biodiesel. Various parts of the tree are also used in traditional medicine and recent research has established its medicinal value including larvicidal activity (Srinivasan et al. 2003; Perumalsamy et al. 2015). However, the yield of essential oils and plant extracts are significantly low making it a non-viable application. For better value addition, alternate applications are to be found out. Using the plant as an alternate source of fiber or as reinforcement in composites is a straightforward and viable option. 
In this research $M$. pinnata fibers were isolated using the alkali solution method from the stalks. The fibers were characterized for its surface morphology, thermal stability, X-ray diffractometry, mechanical properties. The fiber and precursor compositional analysis was also carried out. Further, the extracted fibers were reinforced with polypropylene (PP) to fabricate composites and characterized for its mechanical properties. The properties of the fibers and the composites were compared to other lignocellulosic fibers and composites for potential textiles and composites applications.

\section{Materials and methods Materials}

M. pinnata stalks were collected from S-Vyasa University Jigani campus. The stalks were washed with de-ionized water to remove any mud or dirt particles present, dried and used without any treatment. Laboratory grade sodium hydroxide and acetic acid for the extraction process were purchased from Sigma Aldrich, Bangalore. PP web was procured from Indian Oil Corporation, India.

\section{Extraction of fibers}

$M$. pinnata stalks were treated with $1 \mathrm{M} \mathrm{NaOH}$ solution for $90 \mathrm{~min}$ at $120{ }^{\circ} \mathrm{C}$. The stalk-to-alkali ratio was maintained at 1:10. After treatment, the liquid containing dissolved hemicellulose, lignin and other extractives was decanted and disposed. The fibers extracted were thoroughly washed until the $\mathrm{pH}$ of the fibers was neutral. The neutral $\mathrm{pH}$ fibers were later immersed in $10 \%$ acetic acid solution for $10 \mathrm{~min}$ and then rinsed. The fibers were then dried at $110{ }^{\circ} \mathrm{C}$ for $3 \mathrm{~h}$ and stored for further characterization.

\section{Fiber characterization}

The cellulose and hemicellulose content of the stalk and the extracted fibers were carried out using the standard acid detergent and neutral detergent method as described in Guna et al. (2019d). Klason lignin was determined using the sulfuric acid hydrolysis method. Briefly, known weight of stalk and fibers were treated with $72 \%$ sulfuric acid (1:5 ratio of biomass:acid) for $2 \mathrm{~h}$ under constant stirring. The treated solution was then diluted using distilled water to 1:540 ratio and boiled under reflux for $6 \mathrm{~h}$. After, the stipulated time, solution was filtered to obtain the residue. The obtained residue was washed and then dried at $105^{\circ} \mathrm{C}$ for $6 \mathrm{~h}$. The difference in weight was used to calculate the percentage lignin (Ilangovan et al. 2018b). ASTM E 1755-01 was used to estimate the ash content in the samples."

The fibers were tested for their tensile strength on a Universal Tensile Tester (MTS Mechatronics, Ichalkaranji, India) according to the ASTM D 3822-14 standard. Samples from three different sets of extraction were used for the characterization. 20 samples from each set, i.e., a total of 60 samples were tested. The mean and standard deviation was reported and compared with other standard cellulosic fibers.

Scanning electron micrographs of the M. pinnata stalk and fiber were obtained using a Hitachi SU 3500 scanning electron microscope at an operational voltage of $15 \mathrm{kV}$. Before observing, the samples were sputter coated with gold in an ion beam coater for $60 \mathrm{~s}$.

The X-ray diffraction study was conducted using powdered samples of the stalk and fibers in a Bruker D8 Advanced Eco X-ray diffractometer equipped with Bragg-Brentano Focusing geometry. The analysis was done in a $\mathrm{Cu}-\mathrm{K} \alpha$ radiation $(\lambda=1.54 \AA)$ and the scattered radiations were recorded at $2 \theta$ angles varying from $10^{\circ}$ to $65^{\circ}$ using an SSD 160 detector. The readings were analyzed in Origin Lab software and the peak intensities were identified. The Segal method equation was used to calculate the crystallinity index as shown below:

$$
X_{\mathrm{c}}=\frac{\left(I_{002}-I_{\mathrm{am}}\right)}{I_{002}} \times 100 \%,
$$

where $I_{002}$ and $I_{\text {am }}$ are the peak intensities of the crystalline and amorphous materials, respectively (Segal et al. 1959).

A Shimadzu DTG 60 thermogravimetric analyzer was used to determine the thermal degradation of M. pinnata stalk and the extracted fibers. About $10 \mathrm{mg}$ of the powdered specimen was placed in the analyzer and heated from room temperature to $600{ }^{\circ} \mathrm{C}$ at the rate of $20{ }^{\circ} \mathrm{C} /$ $\mathrm{min}$. Air flowing at a rate of $50 \mathrm{ml} / \mathrm{min}$ was supplied during the analysis.

\section{Fabrication of composites}

Extracted fibers of $M$. pinnata were used as reinforcement in polypropylene composites. The fibers were carded using a carding machine several times to get a uniform mat of fiber. Sandwich type pre-pegs were prepared in 50/50 $(\mathrm{w} / \mathrm{w})$ ratio of fiber/PP and compression molded in a hot press at $170{ }^{\circ} \mathrm{C}$ for $120 \mathrm{~s}$ at 3000 PSI. Cold water was then let through the press and the samples were taken out once the temperature of the press dropped below $80{ }^{\circ} \mathrm{C}$. The composite was then cut to ASTM D 638-14 standard for tensile tests and D 79015 for flexural tests. The mechanical testing was carried out on a Universal Tensile Tester (MTS Mechatronics, Ichalkaranji, India) using appropriate load cells. At least 15 samples were tested for its tensile and flexural properties and the average and standard deviation was reported. 


\section{Results and discussion \\ Compositional analysis}

Generally, composition of fibrous materials depends mainly on the function, growing and extraction conditions (Ilangovan et al. 2018b). Cellulosic fibers are covered by sheaths of lignin and hemicellulose. Upon treatment, the hemicellulose and lignin are washed away exposing the fiber bundles. The reduction in the percentage composition of hemicellulose is attributed to the cleavage of ester-linked substances of hemicellulose, particularly the $\alpha-(1-6)$ linkage in galactose which is sensitive to alkali treatment (Jeffries 1994). The alkali treatment of the $M$. pinnata stalk increased the percentage composition of cellulose in the fiber by $65 \%$ and decreased that of hemicellulose by nearly half its original value (Table 1 ). The lignin content was not significantly reduced as in the case of hemicellulose. It should be noted that excessive removal of hemicellulose will result in shorter fibers which may not be suitable for high-value applications.

\section{Fiber tensile properties}

During the extraction, fibers of lengths up to $6 \mathrm{~cm}$ could be extracted. The fibers were comparatively coarser than common textile fibers; however, they should be processable by regular textile-processing techniques. The tensile strength of the fiber was $310 \mathrm{MPa}$, slightly lower than that of cotton. The elongation of the fibers was found to be $1.83 \%$ which is comparable to linen. A comparison of mechanical properties of common cellulosic fibers and plant residue-based fibers is given in Table 2. M. pinnata fibers show promising potential to be used in textiles, composites.

Table 1 Composition of the M. pinnata stalks and fibers extracted from the plant

\begin{tabular}{lll}
\hline Composition & Stalk & Fiber \\
\hline Cellulose, \% & $32.6 \pm 1.6$ & $54.6 \pm 1.3$ \\
Hemicellulose, \% & $24.8 \pm 1.0$ & $12.3 \pm 0.2$ \\
Lignin, \% & $18.3 \pm 1.6$ & $15.7 \pm 1.3$ \\
Ash, \% & $16.6 \pm 1.3$ & $11.2 \pm 0.6$ \\
\hline
\end{tabular}

\section{Fiber morphology}

The stalks had several impurities and deposits as can be seen from Fig. 1. Alkali treatment significantly removed the impurities; however, the impurities are not completely washed away. Further magnification of fibers shows smaller deposits on the fiber surface. Nevertheless, the surface is seen to be smoother compared to the unprocessed stalks. A more rigorous extraction method can lead to lesser deposits, but could potentially damage the fiber bundles. The fiber bundle width ranged from 50 to $70 \mu \mathrm{m}$ with significant variations throughout the sample set. Individual fibrils ranged from 4 to $8 \mu \mathrm{m}$. The bundle width was comparable to the value reported from cotton stalk fibers $(75 \mu \mathrm{m})$, rice and wheat straw (Reddy and Yang 2009). In the literature, individual fibrillar width of cotton ranged from 12 to $25 \mu \mathrm{m}$ which was much higher than the $M$. pinnata fibers. The properties of any of the fibers are highly dependent on the length and width of the individual fibrils. Longer fibrils result in a finer fiber, whereas shorter ones lead to coarser fibers such as in this case. However, M. pinnata is not a conventional source of fiber and coarseness of extracted fibers is inevitable.

\section{XRD analysis}

The XRD plot of the stalk and M. pinnata fibers is given in Fig. 2. The diffractogram plot shows typical cellulosic peaks at the $2 \theta$ value $22.6^{\circ}$. These peaks are related to the crystalline structure of Cellulose I. The low diffraction intensity at a $2 \theta$ value of $18^{\circ}$ characterizes the amorphous background. The percentage crystallinity of the stalk and the $M$. pinnata fibers were determined to be $53 \%$ and $57 \%$, respectively. In comparison, cotton fibers had a percentage crystallinity of $62.3 \%$. Also, the two smaller peaks at $14.9^{\circ}$ and $16.6^{\circ}$ seen in the cotton fibers were absent in the $M$. pinnata fibers attributed to the presence of hemicellulose and lignin particles in the latter. Such behavior was also observed in other non-traditional fibers (Reddy and Yang 2009). The crystallinity or ordered crystalline arrangements in cellulose fibers arises due to the intermolecular and intramolecular hydrogen bonding via hydroxyl groups. Here the crystallinity of the fiber increases as a result of the extraction process which could be attributed to the

Table 2 Comparison of the tensile properties of $M$. pinnata fibers and other common sources of plant fiber (Guna et al. 2019c; llangovan et al. 2018b)

\begin{tabular}{|c|c|c|c|c|c|}
\hline Fiber properties & M. pinnata & Cotton & Linen & Switch grass & Jute \\
\hline Tensile strength, $\mathrm{MPa}$ & 310 & $392-511$ & $667-885$ & $715 \pm 130$ & $393-800$ \\
\hline Tensile modulus, GPa & 7.5 & $8.0-13.1$ & $28.3-29.7$ & $31.4 \pm 9.5$ & $10-30$ \\
\hline Elongation, \% & 1.8 & $6.0-9.0$ & $1.6-3.3$ & $2.2 \pm 0.7$ & $1.5-1.8$ \\
\hline
\end{tabular}




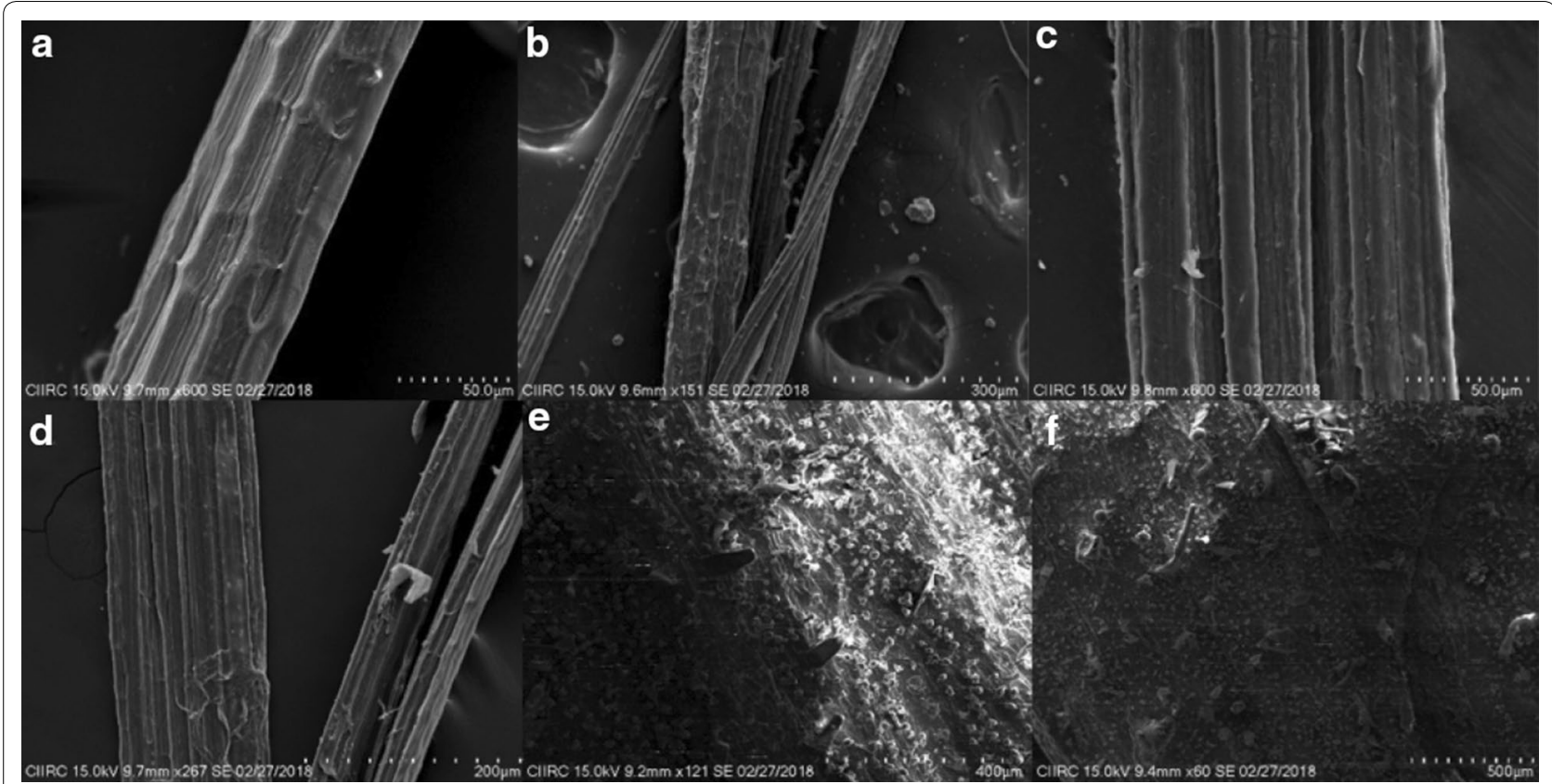

Fig. 1 Scanning electron microscope images of M. pinnata stalk and extracted fibers. a-d Surface features of the fibers, e-f surface features of the stalk

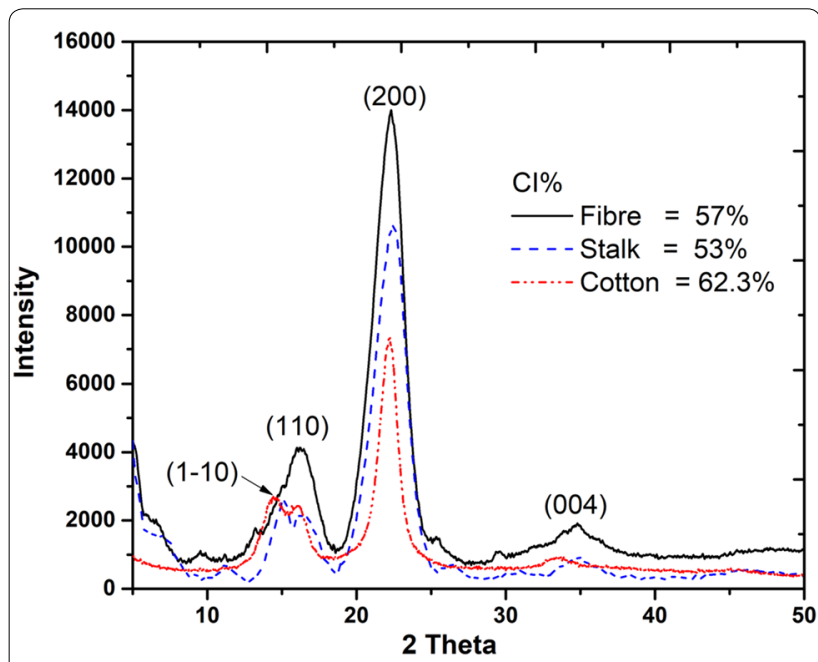

Fig. 2 X-ray diffractogram of M. pinnata stalk (before extraction) and extracted fibers compared with cotton fiber

removal of lignin and amorphous hemicellulose. Some additional peaks can be seen in the untreated stalk diffraction curve, presumably from minerals and impurities present in it. The value of crystallinity obtained in M. pinnata fibers compared to other non-traditional fibers is greater than that of turmeric plant residue

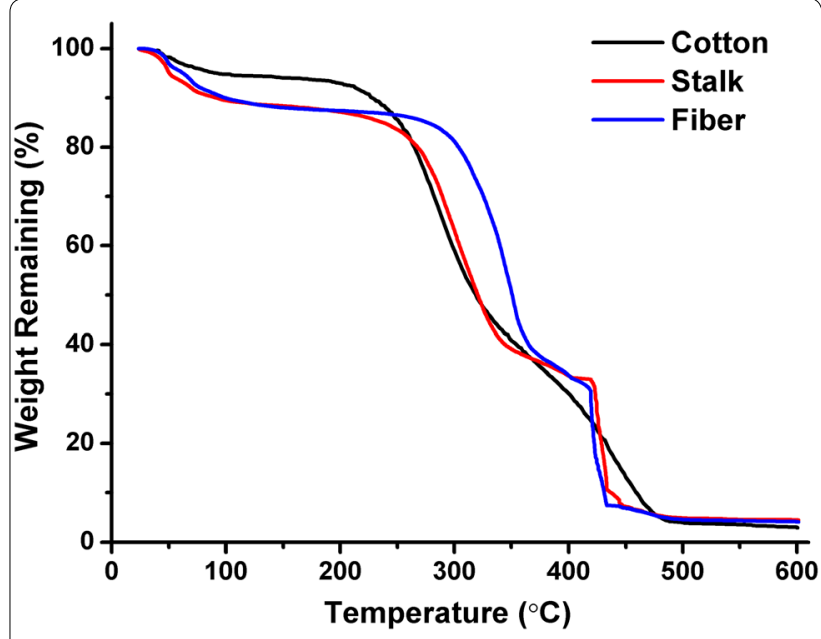

Fig. 3 TGA curves for the thermal degradation of M. pinnata stalks and extracted fibers compared with cotton fibers

(33\%) and M. pinnata seed hull (47\%), but less than that of Mengkuang leaf fibers (Kargarzadeh et al. 2012; Manjula et al. 2017; Ilangovan et al. 2018b).

\section{Thermal stability}

The results of the thermogravimetric analysis can be seen in Fig. 3. The untreated M. pinnata stalk starts degrading thermally at $260{ }^{\circ} \mathrm{C}$, whereas the treated fibers start 
Table 3 Tensile and flexural properties of $50 / 50$ ratio of $M$. pinnata/PP composites compression molded at $170{ }^{\circ} \mathrm{C}$ compared with cotton stalk fiber and jute PP composites

\begin{tabular}{|c|c|c|c|c|c|}
\hline \multirow[t]{2}{*}{ Reinforcement } & \multicolumn{2}{|c|}{ Tensile properties } & \multicolumn{2}{|c|}{ Flexural properties } & \multirow[t]{2}{*}{ Reference } \\
\hline & Strength (MPa) & Modulus (MPa) & Strength (MPa) & Modulus (MPa) & \\
\hline Cotton stalk fiber & $15.7 \pm 3.4$ & $806 \pm 140$ & $12.4 \pm 2.2$ & $502 \pm 99$ & Reddy and Yang (2009) \\
\hline Jute & $13.5 \pm 1.3$ & $979 \pm 98$ & $15.1 \pm 1.0$ & $620 \pm 72$ & Reddy and Yang (2009) \\
\hline M. pinnata & $17.96 \pm 1.1$ & $875 \pm 66$ & $10.1 \pm 0.6$ & $580 \pm 51$ & This work \\
\hline
\end{tabular}

showing thermal degradation only after $300{ }^{\circ} \mathrm{C}$. The weight loss in the initial phase is attributed to water evaporation from the samples. The rapid thermal degradation seen after that from around $260-400{ }^{\circ} \mathrm{C}$ can be attributed to the thermal depolymerization of hemicellulose and pyrolysis of cellulose (Chen et al. 2011; Ludueña et al. 2011; Haafiz et al. 2013). The last streak of weight loss after $420{ }^{\circ} \mathrm{C}$ corresponds to the burning of ash. The final percentage residue recorded for the untreated stalks and the fibers were $7 \%$ and $2 \%$, respectively. Similar residual percentage (3.8\%) with the same three-step degradation mechanism was also observed in cotton fibers.

\section{Composite properties}

The mechanical properties of the composites developed are given in Table 3. M. pinnata fibers showed better tensile properties than cotton or jute-reinforced polypropylene composites, but lower flexural properties. The tensile performance could be due to the fact that the $M$. pinnata fibers are inherently stronger than cotton or jute. Since it is a coarser fiber, the area available for binding of polypropylene is considerably higher than that of cotton and jute. Although the properties of M. pinnata are compared to that of cotton and jute from other authors' works, the fabrication conditions are different. Hence, the comparison should be analyzed with caution. However, $M$. pinnata like any other natural fiber shows potential for use in composite applications and further work to determine the exact behavior of $M$. pinnata fibers will lead to a clearer understanding. Since, the morphological interactions are promising, we intend to carry out an extensive study of the mechanical properties of $M$. pinnata fiber-reinforced composites in another study.

\section{Conclusion}

Cellulose fibers were successfully extracted from M. pinnata plant using alkali treatment. Percentage cellulose increased after the treatment on stalks due to which the crystallinity of the fiber was higher than the stalk. The fibers had properties similar to that of other lignocellulosic fibers. There was an increase in the thermal stability of the fibers compared to the untreated stalk. Mechanical properties of the fiber-reinforced PP composites were comparable to other lignocellulosic composites. M. pinnata fibers can be potentially used in textiles and major composites applications. The use of extracted $M$. pinnata stalk fibers for other industrial applications can be further explored in future research considering the favorable properties of high crystallinity and thermal stability.

Abbreviations

M. pinnata: Millettia pinnata; PP: polypropylene.

\section{Acknowledgements}

The authors thank S-VYASA University for the support they extended during the experimentation.

\section{Authors' contributions}

PBM and SPT are the primary contributors of this work. VG and GRA supported in the preparation of the manuscript. All authors read and approved the final manuscript.

\section{Funding}

Not applicable.

Availability of data and materials

The datasets used and/or analyzed during the current study are available from the corresponding author on reasonable request.

Ethics approval and consent to participate

Not applicable.

Consent for publication

Not applicable.

Competing interests

The authors declare that they have no competing interests.

Author details

${ }^{1}$ Center for Energy Research, S-VYASA University, Jigani, Bangalore, Karnataka 560105, India. ${ }^{2}$ Center for Incubation, Innovation, Research and Consultancy, Jyothy Institute of Technology, Thataguni Post, Bangalore, Karnataka 560082, India. ${ }^{3}$ Visvesvaraya Technological University-Research Resource Centre, JnanaSangama, Belagavi, Karnataka 590018, India. ${ }^{4}$ Department of Mechanical Engineering, Presidency University, Itgalpur, Rajanakunte, Yelahanka, Bangalore, Karnataka 560064, India.

Received: 3 October 2019 Accepted: 30 December 2019 Published online: 07 January 2020

\section{References}

Bhuvaneswari HB, Vinayaka DL, Ilangovan M, Reddy N (2017) Completely biodegradable banana fiber-wheat gluten composites for dielectric applications. J Mater Sci 28(17):12383-12390 
Chen W, Yu H, Liu Y, Hai Y, Zhang M, Chen P (2011) Isolation and characterization of cellulose nanofibers from four plant cellulose fibers using a chemical-ultrasonic process. Cellulose 18(2):433-442

Guna VK, Murugesan G, Basavarajaiah BH, Ilangovan M, Olivera S, Krishna V, Reddy N (2016) Plant-based completely biodegradable printed circuit boards. IEEE Trans Electron Devices 63(12):4893-4898

Guna V, Ilangovan M, Anantha Prasad MG, Reddy N (2017) Water hyacinth: a unique source for sustainable materials and products. ACS Sustain Chem Eng 5(6):4478-4490

Guna V, llangovan M, Nataraj D, Reddy N (2018) Bioproducts from wheat gluten with high strength and aqueous stability using cashew nut shell liquid as plasticizer. J Appl Polym Sci 135(43):46719

Guna V, Ilangovan M, Hu C, Venkatesh K, Reddy N (2019a) Valorization of sugarcane bagasse by developing completely biodegradable composites for industrial applications. Ind Crops Prod 131:25-31

Guna V, Ilangovan M, Rather MH, Giridharan BV, Prajwal B, Krishna KV, Venkatesh K, Reddy N (2019b) Groundnut shell/rice husk agro-waste reinforced polypropylene hybrid biocomposites. J Build Eng 27:100991

Guna V, Ilangovan M, Nagananda GS, Venkatesh K, Reddy N (2019c) Biofibers and biocomposites from sabai grass: a unique renewable resource. Carbohyd Polym 218:243-249

Guna V, Ilangovan M, Hu C, Nagananda GS, Ananthaprasad MG, Venkatesh K, Reddy N (2019d) Antimicrobial natural cellulose fibers from Hyptis suaveolens for potential biomedical and textiles applications. J Nat Fibers. https ://doi.org/10.1080/15440478.2019.1658258

Haafiz MM, Eichhorn SJ, Hassan A, Jawaid M (2013) Isolation and characterization of microcrystalline cellulose from oil palm biomass residue. Carbohyd Polym 93(2):628-634

Ilangovan M, Guna V, Olivera S, Ravi A, Muralidhara HB, Santosh MS, Reddy N (2017) Highly porous carbon from a natural cellulose fiber as high efficiency sorbent for lead in waste water. Bioresour Technol 245:296-299

Ilangovan M, Guna V, Keshavanarayana G, Reddy N (2018a) Tensile and flexural properties of polypropylene composites reinforced with raw bagasse. Sugar Tech 20(4):454-463

Ilangovan M, Guna V, Hu C, Nagananda GS, Reddy N (2018b) Curcuma longa $\mathrm{L}$. plant residue as a source for natural cellulose fibers with antimicrobial activity. Ind Crops Prod 112:556-560

llangovan M, Guna V, Hu C, Takemura A, Leman Z, Reddy N (2019) Dehulled coffee husk-based biocomposites for green building materials. J Thermoplast Compos Mater. https://doi.org/10.1177/0892705719876308

Jeffries TW (1994) Biodegradation of lignin and hemicelluloses. Biochemistry of microbial degradation. Springer, Dordrecht, pp 233-277

Kale RD, Getachew Alemayehu T, Gorade VG (2018) Extraction and characterization of lignocellulosic fibers from Girardinia bullosa (Steudel) Wedd.
(Ethiopian kusha plant). J Nat Fibers. https://doi.org/10.1080/15440 478.2018.1539940

Kalita BB, Jose S, Baruah S, Kalita S, Saikia SR (2019) Hibiscus sabdariffa (Roselle): a potential source of bast fiber. J Nat Fibers 16(1):49-57

Kargarzadeh H, Ahmad I, Abdullah I, Dufresne A, Zainudin SY, Sheltami RM (2012) Effects of hydrolysis conditions on the morphology, crystallinity, and thermal stability of cellulose nanocrystals extracted from kenaf bast fibers. Cellulose 19(3):855-866

Ludueña L, Fasce D, Alvarez VA, Stefani PM (2011) Nanocellulose from rice husk following alkaline treatment to remove silica. BioResources 6(2):1440-1453

Manjula P, Srinikethan G, Shetty KV (2017) Biofibres from biofuel industrial byproduct-Pongamia pinnata seed hull. Biores Bioprocess 4(1):14

Mohan NH, Ammayappan L, Sarma DK, Debnath S, Tamuli MK (2017) Characterization of thermal properties of pig hair fiber. J Nat Fibers 14(4):459-465

$\mathrm{Ni} \mathrm{H}$, Li Y, Fu S (2018) Morphological structure and properties of bamboo shell fiber. J Nat Fibers 15(4):586-595

Perumalsamy H, Jang MJ, Kim JR, Kadarkarai M, Ahn YJ (2015) Larvicidal activity and possible mode of action of four flavonoids and two fatty acids identified in Millettia pinnata seed toward three mosquito species. Parasites Vectors 8(1):237

Reddy N, Yang Y (2009) Properties and potential applications of natural cellulose fibers from the bark of cotton stalks. Bioresour Technol 100(14):3563-3569

Segal LGJMA, Creely JJ, Martin AE Jr, Conrad CM (1959) An empirical method for estimating the degree of crystallinity of native cellulose using the X-ray diffractometer. Text Res J 29(10):786-794

Srinivasan K, Muruganandan S, Lal J, Chandra S, Tandan SK, Raviprakash V, Kumar D (2003) Antinociceptive and antipyretic activities of Pongamia pinnata leaves. Phytother Res 17(3):259-264

Vinayaka DL, Guna V, Madhavi D, Arpitha M, Reddy N (2017) Ricinus communis plant residues as a source for natural cellulose fibers potentially exploitable in polymer composites. Ind Crops Prod 100:126-131

Wang C, Bai S, Yue X, Ren Z (2016) Extraction and performance characterization of the carexmeyeriana fiber. J Nat Fibers 13(6):759-768

\section{Publisher's Note}

Springer Nature remains neutral with regard to jurisdictional claims in published maps and institutional affiliations.

\section{Submit your manuscript to a SpringerOpen ${ }^{\circ}$ journal and benefit from:}

- Convenient online submission

- Rigorous peer review

- Open access: articles freely available online

- High visibility within the field

- Retaining the copyright to your article

Submit your next manuscript at $\boldsymbol{\nabla}$ springeropen.com 